\title{
Analysis of factors affecting the technical efficiency of cocoa farmers in the Offinso district -Ashanti region, Ghana
}

\author{
${ }^{1}$ Leonard Kyei, ${ }^{2 *}$ Gordon Foli and ${ }^{1}$ Janet Ankoh \\ ${ }^{1}$ Department of Statistics,University for Development Studies, Navrongo Campus; \\ Navrongo, Ghana \\ ${ }^{2}$ Department of Earth and Environmental Science, University for Development Studies, \\ Navrongo Campus; Navrongo, Ghana \\ ${ }^{*}$ Corresponding author: gordon.foli01@gmail.com, P.O Box 24, Navrongo Campus; \\ Navrongo, Ghana, Tel: +233 20 8134579; +233 26 8134579; Fax: +233 74222321
}

\begin{abstract}
This paper analysed the factors that affect the technical efficiency of cocoa farmers in the Offinso district in Ghana. The study also analysed the basic determinants of technical efficiency, as well as the socio-economic variables that affect their performances. Primary data was collected through the administration of questionnaires. Stata statistical tool was used to estimate the stochastic production frontier function and the inefficiency determinants based on socioeconomic variables of individual farmers. Analyses showed that the model of the production functions were statistically significant at 0.00 . Input factors studied include labour, quantity of fertilizer, pesticides, modern equipments, age of trees and farm sizes. Out of the above, labour and age of trees were not significant. Also, the estimate of inefficiency component showed that, in the exception of the age of farmers, most of the specific characteristics were not significant. It is recommended that the ability to use and adjust properly, factors such as labour, capital and age of farms would lead to increase in output. Also, inefficiency would decrease drastically if variables such as; educational level, farming experience and family size of the farmer are increased.
\end{abstract}

Keywords: Technical efficiency, production functions, stochastic frontier analysis

\section{INTRODUCTION}

The cocoa industry has been the focus of economic growth in all cocoa growing economies [25], where world production of cocoa increased rapidly over the course of the twentieth century [13]. However, the past three decades had suffered a couple of setbacks and fluctuation patterns that varied among specific economies due to many reasons. For example, Gray [13] indicated that, Cocoa production in Ghana reduced from about 400,000 tonnes in 1975/76 season to a low of about 150,000 tonnes in 1983/84, and turned over to about 450,000 tonnes in 1999/2000.

Production in West Africa is characterised by smallholder type production which often involves whole families as working units. These working units are often characterized by low input and output, aging farmers and farms, disease plagued farms, inefficient use of resources, highly de-motivated youth and poor farming strategy [3, 13]. Cocoa farming is a small unsophisticated business as the current planting patterns of cocoa trees make mechanization impractical. Gray [13] and Binam et al. [5] observed that Ghana is the least efficient cocoa producing country among other economies in the West Africa Region, a situation that may probably be due to the multiplicity of the numerous challenges enumerated above. In general terms, Gockowski et al.[12] and, Nkamleu and Ndoye [24] established that in Africa, the cocoa sector thrives on increase in area cultivated rather than improving yield rather than improving technical efficiency. To reverse this trend, stakeholders of cocoa growing economies have resorted to introducing policy reforms into the industry to improve efficiency $[9,17]$. Low production efficiency means that output can be increased without requiring additional conventional inputs and new technology. This implies that empirical measures of efficiency and technical progress is the rational strategy to adopt to improve performance significantly with a given technology, or in the presence of technological gaps [25]. The general output of 
individual farmers therefore largely depends on the various inputs as well as other specific characteristics relevant for the estimation of inefficiency $[2,23,26]$.

Determination of the factors affecting technical efficiency dates back to the early1990s [6, 19], and are evaluated by both parametric and non-parametric techniques [28, 29]. The non parametric technique constitutes Data Envelopment Analysis (DEA) and requires linear programming based on the input and output quantities [10]. The parametric technique is also based on the stochastic frontier analysis (SFA), which was first proposed by Aigner et al. [1] and Meeusen and Van den Broeck [21]. The SFA uses assumptions on the distribution of an unobserved productivity component to separate productivity from the deterministic part of the production function and the random error. Estimating relative technical efficiencies of firms are thus based on information extracted from extreme observations from a body of data to determine the best practice production frontier to achieve the relative measure $[10,18]$.

Battese and Coelli [4], evaluating for technical efficiency of Indian paddy rice producers found a positive relationship between the degree of inefficiency and the producer's age and a negative relationship with the educational level of the producer. Weir and Knight [36] established in Ethiopia that household education positively influenced the level of technical efficiency in cereal crop farms. In the Brazilian Center-West, access to credit institutions, supply of public sector utilities, technical assistance, and use of modern inputs like fertilizers, practice of irrigation, soil conservation and crop protection against pests are the factors responsible for differences in the level of inefficiency between plantations [14].

On farm sizes, Heshmati and Mulugeta, [16]; Mochebelele and Winter-Nelson, [22]; Townsend et al., [34] found no significant variation in technical efficiency, but Tadesse and Krishnamoorthy [32] reported an inverse relationship while Helfand [15] established a quadratic relationship. Wadud and White [35] observed that inefficiency decreased with farm size, while Shanmugam and Venkataramani [31], Weir and Knight [36] and Seyoum et al. [30] found a positive influence with household education. In West African for example, Ghana and Nigeria had negative education impact, while Cameroon and La Côte d'Ivoire had a positive education impact [5].

Tchale [33] reported about improved efficiency with the quantity and productivity of household labour, which directly contradicts findings by Masterson [20], who also observed that efficiency was inversely related to productivity. Mochebelele and WinterNelson [22] found no useful effect of gender of the household head on technical efficiency. Owens et al. [27], Shanmugam and Venkataramani [31] and Chirwa [7] studied the effect of technical efficiency on extension services, education, health and infrastructure and seed type and together with many others observed mixed outcomes particularly for education, as noted from the key West African cocoa producing states [9].

From the foregoing review, it is clear that technical efficiency is hugely influenced by the inefficient allocation of resources as well as numerous socioeconomic variables which are of varied characteristics [9]. In Ghana studies were concentrated on determining productivity with little attention given to efficiency levels; however it is possible to increase agricultural production significantly, simply by improving the level of producer technical efficiency without additional investments [5, 9]. Increasing productivity and efficiency requires a good knowledge of the current inherent efficiency or inefficiency and related factors. The efficient allocation of resources for development purposes and the factors of production need to be effectively mobilized to reduce the gap between actual and potential national outputs in order to reap the far reaching benefits [3].

The use of empirical measurement provides clearer evidence [8] of the impact of some factors on the performance level rather than the use of theory. Also, the formulation of policy measures have probably been hampered by the lack of relevant empirical studies at critical areas, considering the diversity in results of factors of the same kind at many sites of study as indicated earlier in the text. Such empirical study will obviously pave way for challenges at specific sectors to be addressed on the merits that they deserve, rather than trying to provide solutions for regional or national issues, such as on the West African region an entire country of concern within such regions [3; 9, 25].

The objective of this study is to identify factors determining technical efficiency of cocoa farmers in

the Offinso district of Ashanti region in Ghana in order to:

- Estimate the level of technical efficiency of cocoa farmers in the study area. 
- Identify and analyse factors affecting the performance of cocoa farmers.

- To make sustainable policy recommendations to boost production of cocoa.

\section{METHODS OF STUDY}

Study area: Most of the world's cocoa is grown in a narrow belt 10 degrees either side of the equator, and under humid tropical climates with regular rains and a short dry season. Cocoa was first planted in Ghana, now the second highest world producer, in 1879. The study area is the Offinso district of the Ashanti region of Ghana (Figure 1), and located at the extreme north end of Ghana's main cocoa producing region. The district covers a land area of about $1451 \mathrm{~km}^{2}$, and has a population of about 204,555 , estimated at an growth rate of $4 \%$ per annum based on 2000 census figure of 138,190 [11].

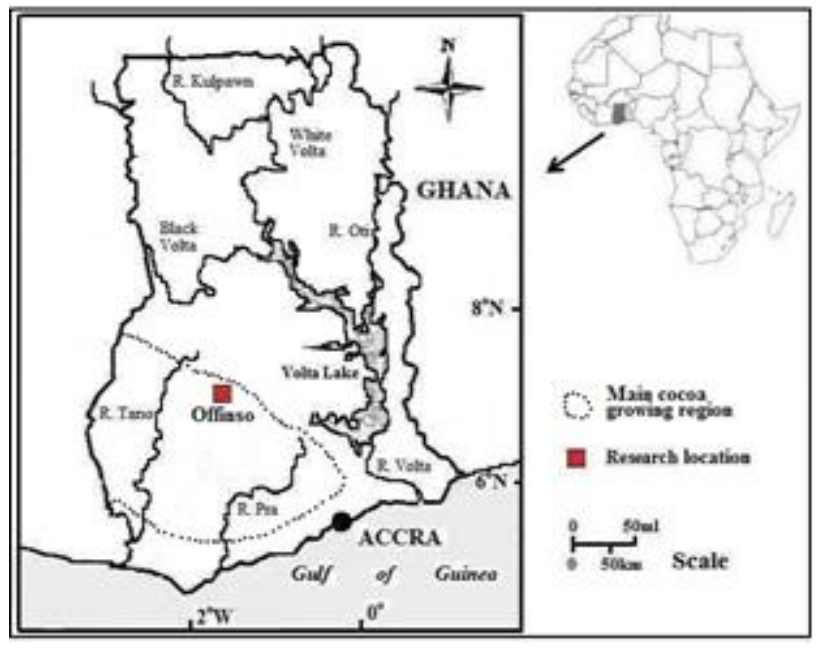

Fig 1: Map of Ghana showing the research location

Sampling technique and data collection: Both primary and secondary data were sourced. Primary data were from the field through interactions with target group (farmers). In all, 100 households were interviewed. Data were collected during the 2009/2010 main crop season using the simple random sampling based on a 'yes or no' balloting to select farmers for the study through the administration of questionnaires with prior briefing of respondents about the objective and aims of the survey. Heads of the households were interviewed, and completed questionnaires carefully validated for consistency. Secondary data were obtained from a regionally based Licensed Buying Company in the Ashanti region.
Measurement of variables: The study used data on technical coefficients (inputs-outputs) of cocoa production, such as land, labour, fertilizers, pesticides and capital. Also used are socioeconomic variables, made up of producer's age, level of education, experience in cocoa production, membership in a mutual aid group, family size, visitations to cocoa farm by agricultural extension officers and the farming practices. The outputs of the various farmers were measured by their total yield in bags per crop season. Land variables were per the total land area in acres cultivated by a farm manager, while labour calculations made were based on the total number of people employed to work on a given size of land in a particular crop season.

The fertilizer variable was measured by the quantity applied by the farm manager in kilograms, and this depended on the age of farm and farming practices. Older farms and mono-cropping system required higher amounts of fertilizer, whilst newer farms and mixed cropping or the rotative system required less. The producer's educational level and experience were determined by the number of years spent in school and in cocoa farming. Family size was determined by the number of people living in the household during the crop year. Agricultural extension workers' contact with the farms is calculated through the number of visitations to plantations during the crop season.

Statistical package and analytical order: The stata and excel software were used for the analysis of data collected. Data was first analyzed on an exploratory basis by primarily interrogating 100 respondents on the basis of sex distribution, age distribution, educational level, credit facility and technical assistance. This was followed by preliminary analysis with the aim of testing for the significance and the relationship that existed between the input factors. This was done by cross tabulating the known variables and estimating their significance level using the Chi- square test for the application the null hypotheses.

The final stage involved further analysis by the application of the specified model of the Stochastic Frontier Analysis model, in which the production output of a particular farm was taken to be the dependent variable whilst the individual variables determined above constituted the independent variables. For meaningful results, the following generalized null hypotheses were formulated study: 
- Offinso cocoa farmers are technically efficient and would produce at a maximum of expected output, given the required factor inputs of production.

- The age, educational level and experience of farmers, membership in a mutual aid group, family size, agricultural extension workers' contact with cocoa plantations, accessibility to credit, and the practice of modernized farming systems, among other factors do not significantly influence the farmer's technical efficiency.

With the above null hypotheses, factors that significantly influence the performance of farmers within the study area, as well as the socio-economic variables that affect the inefficiency of the cocoa farmers can now be evaluated.

\section{RESULTS AND DISCUSSION}

Results from primary data showed that about $74 \%$ of cocoa farmers within the study area are males and $26 \%$ are females (fig. 2).

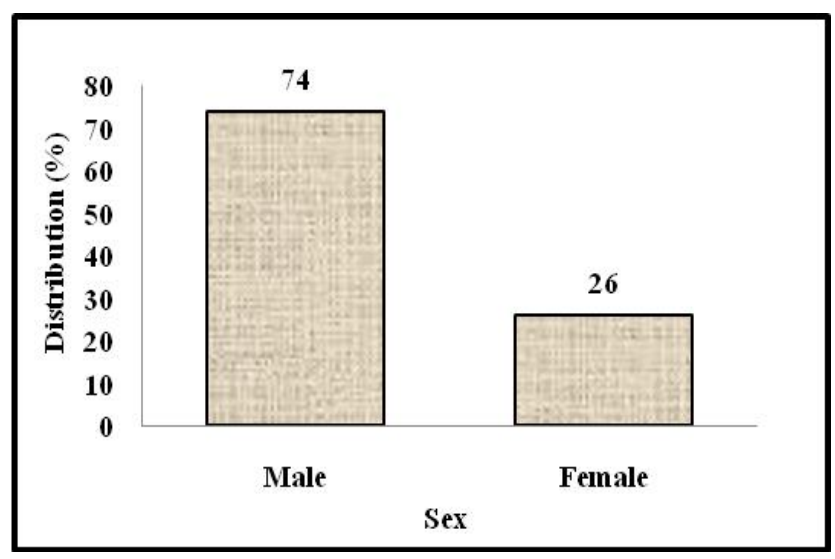

Fig 2: Sex distribution of farmers

From figure 3 , all the respondents were above the age group of 20-30 years, with the highest age bracket being 61 years and above recorded as much as $37 \%$.

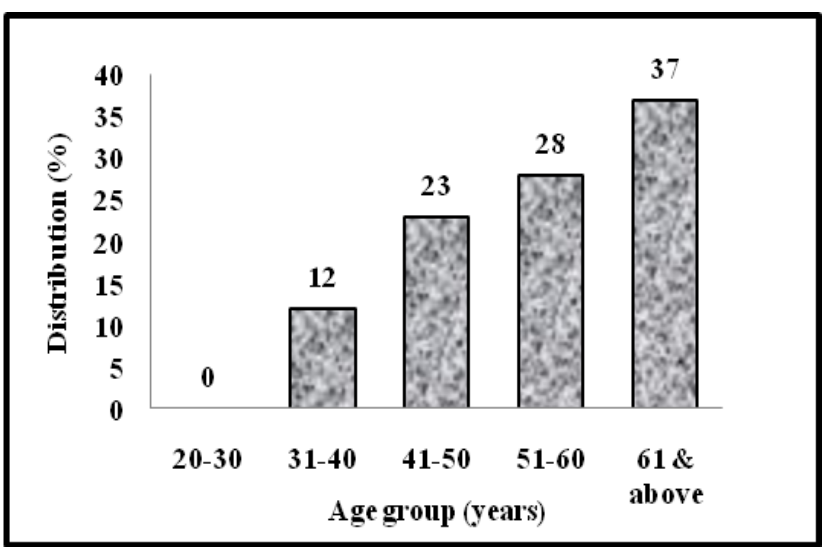

Fig 3: Age distribution of farmers

From figure $4,51 \%$ of farmers had primary level education, $19 \%$ had secondary level, while $30 \%$ had no level of education. Also, only $14 \%$ had access to credit facility (fig. 5), while $61 \%$ had technical assistance (fig. 6). Credit facility was not easily acquired by farmers may probably be due to stringent measures required for such acquisitions. That notwithstanding, incentives and/or training schemes served as a form of motivation to boost morale among farmers. Examples of these incentives are government bonuses on production, mass spraying exercise to control production related diseases, commissions paid to farmers by the various Licensed Buying Companies (LBC). Analysis showed that $73 \%$ of respondents had access to these classes of incentives. Labour, had a negative relationship with output for a given piece of land.

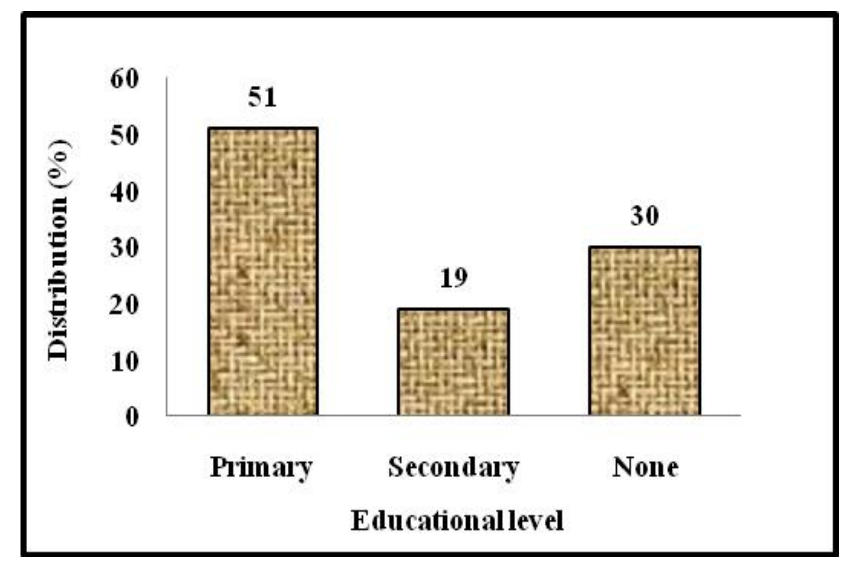

Fig 4: Distribution of the educational level of farmers 


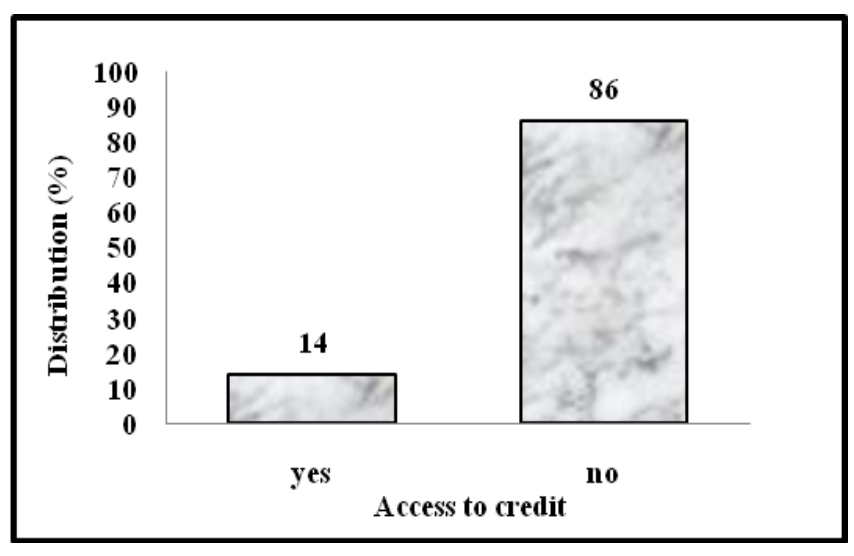

Fig 5: Access to credit assistance by farmers

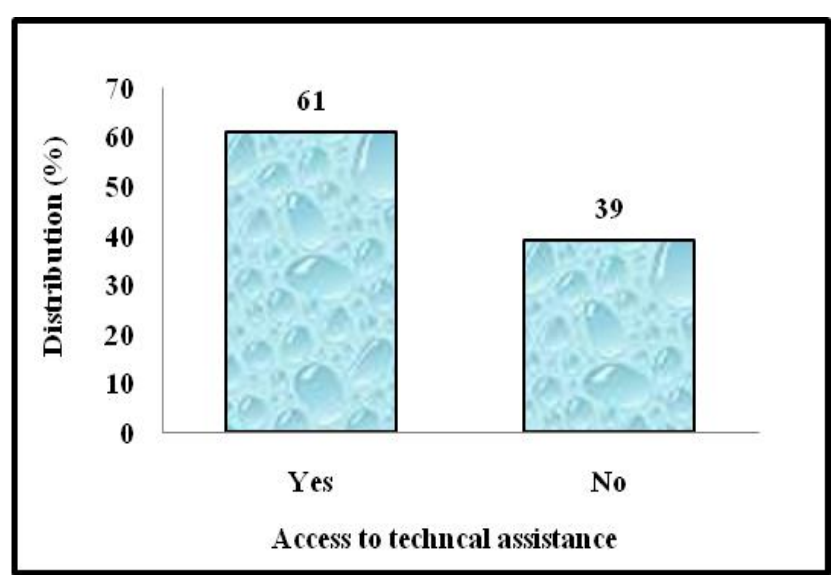

Fig 6: Provision of technical assistance to farmers

The chi-square test was conducted to find associations to evaluate sub-hypotheses coined from the generalized hypotheses stated above. In these analyses comparative test were also carried out to determine the significance level of certain factors and their dependency on others.

The test was conducted with a null hypothesis as, the level of education is independent on the gender of the farmer, and the p-value was 0.011 which is significant at $5 \%$ level of significance, so we reject the null hypothesis and thus concludes that the level of education is dependent on the gender of the farmer.

The next test was conducted with a null hypothesis as the level of education is independent of the age of the farmer, the chi-square $p$-value was found to be 0.44 which is not significant at $5 \%$ level of significance, so we fail to reject the null hypothesis and conclude that the level of education of a farmer is independent on the age of that individual farmer.
We further, tested the null hypothesis that the Labour force of a farmer is independent of the size of the family of the farmer. The chi-square $p$-value was 0.002 which is significant at $5 \%$ level of significant. So we reject the null hypothesis in favour of the alternative that the labour force of a farmer is dependent on the family size of the farmer.

We furthermore, tested the null hypothesis that the age of a cocoa tree is independent on the age of the cocoa farm. The chi-square $p$-value was found to be 0.000 which is significant at $5 \%$ level of significance, so we reject the null hypothesis in favour of the alternative that, the years of a cocoa tree is dependent on the age of the cocoa farm.

Also, we conducted another test with the null hypothesis that the production output of a farmer is independent of the quantity of fertilizer used during the past season. The chi-square $p$-value was found to be 0.000 which is significant at $5 \%$ level of significance, so we reject the null hypothesis in favour of the alternative that the production output of the farmer is dependent on the quantity of fertilizer used during the past season.

Finally, a test of a null hypothesis as the production output is independent on the quantity of pesticides used. The chi-square $p$-value was found to be 0.017 which is significant at $5 \%$ level of significance so we reject the null hypothesis in favour of the alternative that the production output is dependent on the quantity of pesticides used.

For further Analyses, stochastic estimations technique has the model form as;

$$
\operatorname{In} Y_{j}=f\left(X_{i j} ; \beta\right)+\varepsilon_{j}
$$

In Represents a natural logarithm

$Y_{j}$ Represents the total output of farm j

$f$ Represents the function of the inputs of farm j

$X_{i j}$ Represents the input $\mathrm{i}$ of farm $\mathrm{j}$

$\varepsilon_{j}$ Represents the random error of farm $\mathrm{j}$

From the above, the model for the data analysis could be given as;

$$
\ln Y_{j}=\beta_{0}+\sum_{i=1}^{6} \beta_{i} \ln X_{i j}+\varepsilon_{j}
$$


Based on a regression procedure that was used to run on the data, the model summary above fitted a regression model of the form;

$$
\begin{aligned}
& Y_{j}=49.293+0.685 X_{1}+1.192 X_{2}+1.046 X_{3}-1.231 X_{4}-12.419 X_{5}-0.249 X_{6} \\
& -449.326 \text {. }
\end{aligned}
$$

$Y_{j}$ Is the total output of farm $\mathrm{j}$ for the particular crop season

$X_{1}$ Is the total quantity of bags of fertilizer used during the previous crop season

$X_{2}$ Is the total quantity of pesticides (litres) used during the crop year

$X_{3}$ Is the total land area cultivated by the farmer (acres)

$X_{4}$ Is the labour employed by the farmer (hired or from family stocks)

$X_{5}$ The modern equipment available for the farmer's usage

$X_{6}$ The years of cocoa trees in the farm

$\varepsilon_{j}$ Is the error term which measures the inefficiency of farm j.

The model gives the magnitude of the effect of the various factors on total output. It is realized that, labour force has a negative correlation with production output and was also found to be insignificant at 5\% confidence interval. This implies that, a unit increase in labour would decrease total output by $123 \%$. Also, modern equipment and age of trees have very strong negative correlation with output. This means that, there would be a general decrease of $1241 \%$ and $24 \%$ in output by a unit increase of modern equipment and age of trees respectively. Though, modern equipment yielded a negative relation to output, it is significant at 0.02 whilst age of trees is not significant at 0.13 of $5 \%$ level of confidence interval. This seem to suggest that in the study area, cocoa productivity could be enhanced by improving technical efficiency using empirical data generated as stated earlier in the text.

Factors such as quantity of fertilizer used, pesticide used and farm size have positive relationship with output. These imply that, a unit increase in fertilizer usage, pesticides and farm size will yield a percentage increase of output at 68, 119 and 104 respectively. The analysis however showed that, farm size was insignificant at 0.06 whilst fertilizer and pesticides were significant at 0.00 and 0.01 respectively at $5 \%$ level of significance. This could further be interpreted as that, unlike fertilizer and pesticide usage, output does not necessarily depend on the farm size and so conformed to observations by Heshmati and Mulugeta, [16]; Mochebelele and Winter-Nelson, [22]; Townsend et al., [34], but flatly contravenes the collective reports by Tadesse and Krishnamoorthy [32], Helfand [15] and Wadud and White [35]. Gockowski et al., [12] and Nkamleu and Ndoye, [24] confirmed the latter information for the sector in Africa, where output has been achieved by increasing the area cultivated rather than by improving yield; a situation that seems to oppose findings of the study.

Another way of determining technical efficiency of a firm, is by highlighting factors of inefficiency as well; the error term therefore in the model describes the inefficiency of the sector and could be achieved by regressing the individual error terms of the farmers on their specific characteristic. The inefficiency model is given as;

$\mu_{j}=\delta_{0}+\sum_{I=1}^{10} \delta_{I} X_{i j} \ldots \ldots \ldots \ldots \ldots \ldots \ldots$

$\mu_{j}$ Is the error term of farm $\mathrm{j}$

$\delta_{i}$ Is the constants of variable characteristic $\mathrm{i}$

$X_{i j}$ Represents the specific characteristics i of farm $\mathrm{j}$

With input from the necessary run on the data, the following expression is obtained.

$$
\begin{aligned}
\mu_{j}=0.9756 & +0.0083 X_{1}-0.0006 X_{2}-0.0026 X_{3}-0.0004 X_{4}-0.0181 X_{5} \\
& +0.0133 X_{6}+0.0101 X_{7}+0.0017 X_{8}-0.0109 X_{9} \\
& +0.0001 X_{10} \ldots \ldots \ldots \ldots \ldots \ldots \ldots \ldots \ldots \ldots \ldots \ldots \ldots \ldots \ldots \ldots \ldots \ldots \ldots \ldots \ldots \ldots n
\end{aligned}
$$

$\mu_{j}$ Is the degree of inefficiency of farm $\mathrm{j}$

$X_{1}$ ls the age of the farmer

$X_{2}$ Is family size of the farmer.

$X_{3}$ Is the educational level of the farmer

$X_{4}$ Is the farming experience of the farmer

$X_{5}$ Shows whether the farmer belongs to a mutual aid group

$X_{6}$ Shows the access to credit facility 
$X_{7}$ Shows the availability of technical assistance to farmers

$X_{8}$ Shows the economic activity of farmers

$X_{9}$ Shows the availability of incentives or training to farmers

$X_{10}$ Shows the individual farm ages of cocoa plantations

The regression model above shows the relationship between the specific characteristics of farmers and their level inefficiency. The model summary has an estimated R-squared of 0.1326 . This shows that, the factors in the model only account for only $13.26 \%$ of inefficiency. This means that there are other unidentified factors that greatly affect inefficiency level of farmers. By applying the model of technical inefficiency, it was realized that, there exist a positive correlation between the degree of inefficiency and the age of the farmer, access to credit facility, availability of technical assistance, patronage in other economic activity and the age of farms. On the other hand, the level of significance varies with these variables.

With the exception of the constant term that showed a level of significance, all the other variables were not significant at $5 \%$ confidence interval. Age of farmers had a $p$-value of 0.044 ; family size is $0.340,0.509$ for educational level and farm age at a level of 0.844 . A negative relationship was also found to exist between degree of inefficiency and family size of individual farmers, educational level, farming experience, mutual aid and availability of incentives or training. This can also be explained as that; increasing family size would only increase the number of labour required on a piece of land for agricultural purposes and so it would enable the reduction of inefficiency. Increasing the level of education decreases the level of inefficiency. Incentives and training and as well as mutual aid decreases inefficiency and makes the farmer more efficient.

Now that we have the inefficiency component, we can estimate for the individual technical efficiency by using the formula;

$$
T E=\exp \left(-\mu_{j}\right)
$$

Technical efficiency ranges between 0 and 1 . A value of 1 indicates that, the particular farm is technically efficient whilst values close to 0 reveal the degree of inefficiency of the farm considered. The study revealed that, majority of farmers cultivated on a very small scale and just a handful could cultivate above twenty acres of land because of low capital levels to cultivate larger acres of land.

In summary, from the test of association although all the input factors such as usage of fertilizer, pesticides, modern equipment, the farm size, number of labour employed on a given piece of land and the years of tree of cocoa have either a positive or negative relationship with the total output of the farmer. But, priority should be given to those factors that have significant effect to output such as fertilizer and pesticides as well as the usage of modern equipment. Also the specific characteristics (socioeconomic variables) of the individual farmer had either positive or negative correlation with inefficiency. The regression model revealed that, all the variables of inefficiency component were not significant. Therefore, the null hypothesis of the study will be accepted and the conclusion drawn that, the socio-economic variables of the farmer does not significantly affect the degree of inefficiency.

In order to control the level of inefficiency therefore, the direction (negative or positive) of their coefficients is used to determine those variables that increase or decrease the degree of inefficiency of farmers. The analysis also revealed that the average level of efficiency of farmers within the district is 0.0279 . This value is very less and nearer to 0 so, the null hypothesis will be rejected and the conclusion will be drawn that, the farmers are technically inefficient. The results also showed that, only of about $1 \%$ of the farmers are technically efficient and the remaining $99 \%$ are technically inefficient.

\section{CONCLUSION AND RECOMMENDATIONS:}

Most of the respondents were found to be subsistence farmers who only cultivate to sustain themselves and their families. Some of the factors that were identified as affecting their output included land, capital and labour. The preliminary analysis also showed that, some of the factors and socioeconomic variables are dependent of each other whilst other factors too are independent. Education and sex showed a level of significance and therefore dependent, just as production output and fertilizer and pesticide usage; this imply that for a greater yield, use of fertilizer and pesticides needs to be intensified.

Further analysis of the data showed that, some of the input factors of production have negative relationship with output of a specific farm. Factors such as number of labour employed, use of modern equipment and the years of cocoa trees affect 
general output negatively and should be given prior attention. The inefficiency component also had characteristics that showed a positive relationship. From the literature reviewed, the socio-economic variables of the individual farmers was to help estimate the degree of inefficiencies of farmers, however, the model showed that the variables were not significant hence no concrete policy recommendation was made. Recommendations were thus based on only the input factors of the output model, specifically on those that have significant effect on the production output. Farmers often perceive government as solely responsible for inputs such as fertilizer and pesticides and even and other simple farming implements. Proper orientation should therefore be given to farmers to take up very simple but pertinent responsibilities. Also, the services of extension officers within the district should be strengthened so that, their impact in the agricultural sector would reflect the production output. Seminars and training for farmers should be regular at least for every crop season in order to bring farmers to speed about emerging trends.

Acquisition of loan facilities should be made flexible so that more farmers could acquire enough inputs to expand their farming activities. In addition to seasonal bonuses to farmers, increased incentives such as insurance, needs to be provided. Also, instead of leaving the mass spraying exercise solely in the care of the district management, efforts are needed to entrust such a responsibility to farmers directly to administer themselves, since most of them are not given the needed attention. Technical assistance should also be made more accessible to all farmers within the district irrespective of the individual's status and influence. Finally the youth should be encouraged to take up the challenge and devote themselves to the cocoa sector.

\section{ACKNOWLEDGEMENT}

Acknowledgements go to all and sundry who in diverse ways helped in making this research a success.

\section{REFERENCES}

1. D. Aigner, K. Lovell, and P. Schmidt. 'Formulation and estimation of stochastic frontier production function models.' Journal of Econometrics 6(1) pp.21-37, 1977.

2. D. Amargan. Determining the Factors Affecting Efficiency in Agriculture. International Journal of Agricultural research 3 (4) pp.325-330, 2008.
3. T.T. Amos. An Analysis of Productivity and Technical Efficiency of Smallholder Cocoa Farmers in Nigeria, J. Soc. Sci., 15(2) pp.127-133, 2007.

4. Battese, E. George, and T. Coelli. 'A model for technical inefficiency effects in a stochastic frontier models.' Empirical Economics 20, 1995.

5. J.N. Binam, J. Gockowski, and G.B. Nkamleu. Technical Efficiency and Productivity Potential of Cocoa Farmers in West African Countries, The Developing Economies, XLVI-3: pp. 242-63, 2008.

6. R.E. Caves and D.R. Barton. Efficiency in U.S. manufacturing industries (Cambridge (Mass.): MIT Press), 1990.

7. E.W. Chirwa. Sources of Technical Efficiency among Smallholder Maize Farmers in Southern Malawi, African Economic Research Consortium (AERC) Research Paper 172, 2007.

8. T. Coelli. Specification and estimation of stochastic frontier production functions. Unpublished Ph.D. Dissertation, University of New England, Australia, 1996.

9. R. Dzene. WHAT DRIVES EFFICIENCY ON THE GHANAIAN COCOA FARM? Ghana Institute of Management and Public Administration, Ghana, 2010. www.csae.ox.ac.uk/conferences/2010-

EdiA/papers/498-Dzene.pdf

10. M.J. Farrell. 'The measurement of productive efficiency.' Journal of the Royal Statistical Society. Series A (General) 120(3), 1957.

11. GhanaDistricts.com, 2010. http://en.wikipedia.org/wiki/Offinso_District. Accessed on $08 / 12 / 2010$.

12. J. Gockowski, G.B. Nkamleu and J. Wendt. "Implications of Resource-use Intensification for the Environment and Sustainable Technology Systems in the Central African Rainforest". Book chapter, In DR. Lee and CB; Barrett (eds) Tradeoffs or Synergies? : Agricultural intensification, economic development, and the environment. CAB International, Chapter 11, 2000.

13. A. Gray. The World Cocoa Market Outlook. LMC International Ltd, 2001. www.treecrops.org/crops/cocoaoutlook.pdf

14. S.M. Helfand. Farm Size and Determinants of Productive Efficiency in the Brazilian Centre West; (pp. 605-612) Proceedings of the 25th International Conference of Agricultural Economics, Durban, South Africa, 2003.

15. S.M Helfand. Farm size and the determinants of productive efficiency in the Brazilian Center-West, Agricultural Economics, 31(2-3): pp. 241\{249\}, 2004. 
16. A. Heshmati and Y. Mulugeta. "Technical efficiency of the Ugandan matoke farms". Applied Economic Letters, 3: pp.491-94, 1996.

17. E.O. Idowu, D.A. Osuntogun, and O. Oluwasola. Effects of Market Deregulation on cocoa (Theobroma cacao) production in Southwest Nigeria. African Journal of Agricultural Research Vol. 2 (9), pp. 429434, 2007.

18. A.Y. Lewin and C.A.K. Lovell. Editors Introduction, Journal of Econometrics, 46, pp. 3-5, 1990.

19. C. A. K, Lovell. "Production Frontiers and Production Efficiency." In H. O. Fried, C. A. K. Lovell, and S. S. Schmidt, Editors. The Measurement of Productive Efficiency. Cambridge, England: Oxford University Press, 1993.

20. T. Masterson. Productivity, Technical Efficiency, and Farm Size in Paraguayan Agriculture, the Levy Economics Institute, Working Paper No. 490, 2007.

21. W. Meeusen and J. van den Broeck. "Efficiency Estimation from Cobb-Douglas Production Functions with Composed Error," International Economic Review, 18, pp.435-444, 1977.

22. M.T. Mochebelele and A. Winter-Nelson. "Migrant labour and farm technical efficiency in Lesotho". World Development, 28(1): 143-53, 2000.

23. J. Moses and E.F. Adebayo. Efficiency of Factors Determining Rainfed Rice Production in Ganye Local Government Area, Adamawa State. J. of Sustainable Development in Agriculture \& Environment Vol. 3: pp. 20-30, 2007.

24. G.B. Nkamleu and O. Ndoye. Cocoa Based Farming Systems in Humid Forest Zone of West and Central Africa: Constraints and Opportunities. Proceeding, CORAF/IAC Consultation Workshop on Science and Technology Strategies ... Dakar, Senegal. Inter Academy Council, Amsterdam: The Netherlands, 2003.

25. G.B. Nkamleu, J. Nyemeck and J. Gockowski. Technology Gap and Efficiency in Cocoa Production in West and Central Africa: Implications for Cocoa Sector Development, Working Papers Series No 104. African Development Bank, Tunis, Tunisia, 2010.

26. Ogunyinka E. O. and I. A. Ajibefun. Determinants of Technical Inefficiency on Farm Production: Tobit Analysis Approach to the NDE Farmers in Ondo State, Nigeria: INTERNATIONAL JOURNAL OF
AGRICULTURE \& BIOLOGY 1560-8530/2004/06-2pp. 355-358, 2004.

27. T.Owens, J. Hoddinott and B. Kinsey. "The impact of agricultural extension on farm production in resettlement areas of Zimbabwe: Working Paper CSAE WPS/2001-6. Centre for the Study of African Economies, University of Oxford, UK, 2001.

28. E. Owusu-Ansah, I.K. Dontwi, B. Seidu, G. Abudulai and C. Sebil. Technical efficiencies of Ghanaian general insurers. AMERICAN JOURNAL OF SOCIAL AND MANAGEMENT SCIENCES. ISSN Print: 21561540, ISSN Online: 2151-1559 Doi:10.5251/ajsms.1.1.75.87, 2010.

29. L. Seiford and M. Thrall. Recent Developments in DEA: The Mathematical Programming Approach to Frontier Analysis, Journal of Econometrics, 46(1-2) pp. 7-38, 1990.

30. E.T. Seyoum, G.E. Battase and E.M. Flemming. Technical Efficiency and Productivity of Maize Producers in Eastern Ethiopia: A Study of Farmers within and outside the Sasakawa Global 2000 Project. Agric Econs.19 pp.341- 34, 1998.

31. K.R. Shanmugam and A. Venkataramani. Technical Efficiency in Agricultural Production and Its Determinants: An Exploratory Study at the District Level, Madras School Of Economics, Working Paper 10/2006.

32. B. Tadesse, and S. Krishnamoorthy. Technical efficiency in paddy farms of Tamil Nadu: an analysis based on farm size and ecological zone. Agric. Econ. 16, pp. 185-192, 1997.

33. $\mathrm{H}$. Tchale. The efficiency of smallholder agriculture in Malawi, AFJARE Vol 3 No 2, 2009.

34. R.F. Townsend, J. Kirsten and N. Vink. "Farm size, productivity and returns to scale in agriculture revisited: A case study of wine producers in South Africa". Agricultural Economics, 19: pp.175-80, 1998.

35. A. Wadud and B. White. "Farm household efficiency in Bangladesh: A Comparison of stochastic frontier and DEA methods"; Applied Economics, 32: 1665-73, 2000.

36. S. Weir and J. Knight. "Education externalities in rural Ethiopia: Evidence from average and stochastic frontier production functions". Working Paper CSAE WPS/2000-4. Centre for the Study of African Economies, University of Oxford, UK, 2000 